\title{
Unilateral absence of internal carotid artery: A rare case report
}

\author{
Uddalok Das' ${ }^{1}$, Sahajada Selim ${ }^{1}$, Ramudar Singh', Narayan Pandit ${ }^{2}$ \\ From ${ }^{1}$ Post Graduate Trainee, '2Professor and HOD, Department of Radiodiagnosis, North Bengal Medical College and Hospital, Siliguri, \\ West Bengal, India
}

\begin{abstract}
Unilateral absence of internal carotid artery (ICA) is a rare congenital anomaly. We present the case of a 35-year-old man with episodes of recurrent strokes in the past and now presenting with right-sided upper limb weakness. Radiological diagnostic workup revealed a thin left ICA in the neck with non-visualization beyond petrous bone in the intracranial course. The ipsilateral brain parenchyma is supplied by vessels from the contralateral side of the Circle of Willis. As the patient had no evidence of a cerebrovascular accident on radiological evaluation and no neurological signs and symptoms, he was discharged with anticoagulant medications with the advice of follow-up. This is the first report to describe a case of ICA agenesis with a pattern of collateral circulation that doesn't fit any of the six types described by Lie.
\end{abstract}

Key words: Circle of willis, Agenesis, Congenital absence, Internal carotid artery

$\mathrm{C}$ ongenital absence of the internal carotid artery (ICA) is a rare anomaly occurring in $<0.01 \%$ of the general population [1,2]. Most cases are asymptomatic due to extensive collateral development [3]. The paths of collateral flow are through the circle of Willis, persistent embryonic vessels, or transcranial collaterals developing from the ipsilateral external carotid artery. These patients present with features of cerebrovascular accident or transient ischemic attack. These patients are at an increased risk of the development of aneurysms hence, need periodic screening with angiography. There are only about just more than 100 cases of ICA agenesis reported in world medical literature [4].

\section{CASE REPORT}

A 35-year-old gentleman presented to the emergency of North Bengal Medical College with complaints of spontaneous onset right-sided upper limb weakness for a few hours. He previously had a few episodes of ischemic stroke in the past the last one being 2 years back and was taking medications and physiotherapy irregularly. He was admitted immediately under the Department of General Medicine.

The patient was alert conscious and cooperative oriented to time place and person. All higher functions were normal. Attention, vigilance, memory, and language skill were preserved.

\section{Access this article online}

Received - 13 November 2021

Initial Review - 01 December 2021

Accepted - 07 December 2021

DOI: $10.32677 /$ ijcr.v7i12.3196
Cognition and preservation were normal. No amnesias, aphasia, docility, or hemineglect were noted. There was no bladder or bowel incontinence. No apraxias, alexias, agraphia, agnosias, and disconnection syndromes could be noted. A mini-mental state examination (MMSE) was done and the MMSE score was 26. On admission, he had a pulse rate of 84 beats per minute, peripheral capillary oxygen saturation with fingertip pulse oximeter $97 \%$ in room air, non-invasive blood pressure (NIBP) 110/78 mm Hg, respiratory rate of 15 per min, and an axillary temperature of $98^{\circ}$ Farenheight. The general survey, systemic examination, and neurological examination were unremarkable. There was no neurological deficit.

A Computed Tomography (CT) scan was done from the emergency reception and revealed a few chronic infarcts in the left Middle Cerebral Artery (MCA) watershed zone. There was no evidence of hemorrhage or tell-tale signs of acute infarcts. As he was already on irregular anticoagulant medications, the decision to initiate thrombolysis was withheld for the time being. A Magnetic resonance imaging (MRI) of the brain was ordered. MRI revealed no acute infarct. Multiple chronic infarcts ranging in size from 1 to $2 \mathrm{~cm}$ in the left cerebral hemisphere in the left MCA territory. Few small chronic lacunar infarcts in the left periventricular region. The 3D time of flight (TOF) MR angiography revealed non-visualization of the left ICA beyond the petrous segment. Left MCA was very thin and supplied by the Left posterior communicating artery $(\mathrm{PCoM})$. The left anterior cerebral artery (ACA) was supplied by the anterior communicating artery

Correspondence to: Uddalok Das, Department of Radiodiagnosis, North Bengal Medical College and Hospital, Siliguri, West Bengal, India. E-mail: rikdas05@gmail.com

(C) 2021 Creative Commons Attribution-NonCommercial 4.0 International License (CC BY-NC-ND 4.0). 
(ACoM) (Figs. 1 and 2). MR angiography of the neck revealed a very thin Left ICA which was not visualized beyond the petrous bone in its intracranial course (Fig. 3). The vertebrobasilar system was normal.

The patient was started on Aspirin $75 \mathrm{mg}$ and Clopidogrel $75 \mathrm{mg}$ daily along with Atorvastatin 80mg daily. Routine investigations including coagulation profile were sent and reports were within normal range. Electrocardiogram and echocardiography were done and were unremarkable. The patient's symptoms were attributed to transient ischemic attack as no thromboembolic event or source could be identified. He was kept under observation for $48 \mathrm{~h}$. There were no new signs or symptoms of neurological deficit, and the previous symptom had resolved spontaneously. He was discharged with the same medications and with the advice of regular follow-up.

\section{DISCUSSION}

The first documented case of carotid agenesis was discovered on postmortem examination in 1787 and is credited to Tode [3]. In 1954, Verbiest reported the first case of ICA agenesis at cerebral angiography [5]. Mechanical and hemodynamic stresses over the embryo-like exaggerated folding of embryo toward one side and constriction by the amniotic band have been postulated as a possible hypothesis for agenesis [6,7]. Congenital absence of the ICA is considered a spectrum of rare anomalies. The reported incidence is $<0.01 \%$ in the population $[1,2]$. These

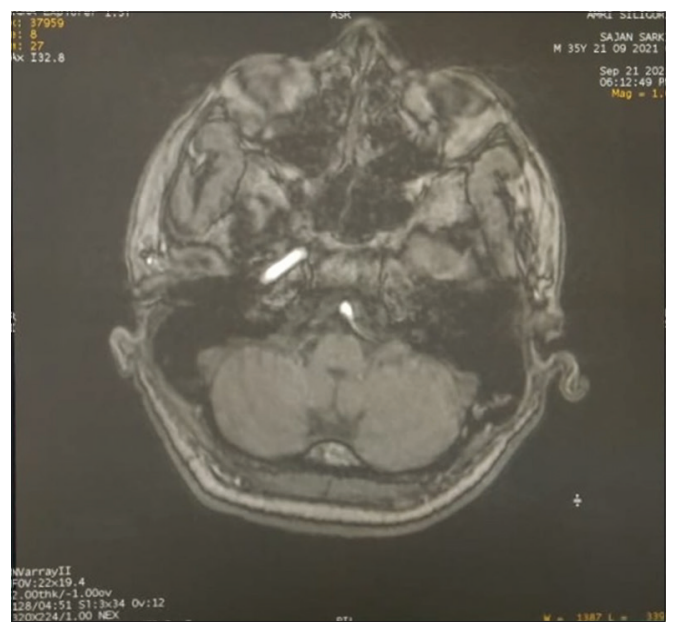

Figure 1: 3D TOF MR angiography showing absence of flow-related signal intensity within the left internal carotid artery
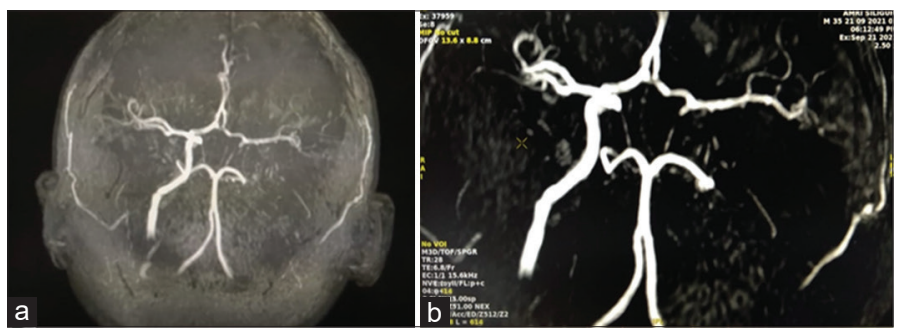

Figure 2: (a) 3D TOF MR Angiography of the circle of Willis showing absent ICA on left and a thin left MCA. Left ACA being supplied by left ACoM and Left MCA being supplied by left PCoM which is not hypertrophied; (b) Zoom-in view of the circulation at Circle of Willis include agenesis, aplasia, and hypoplasia [8,9]. Our cases can be categorized as agenesis. This condition has been seen more often at the left side by 3:1 ratio [10]. Lie described six pathways of collateral circulation in association with the absence of the ICA [11] (Fig. 4).

Our case is however unique as it doesn't fit into any of the ones described. PCoM was supplying MCA but was not hypertrophied. It could be considered as a variation falling between type $\mathrm{A}$ and type $\mathrm{B}$. These cases are relatively rare in

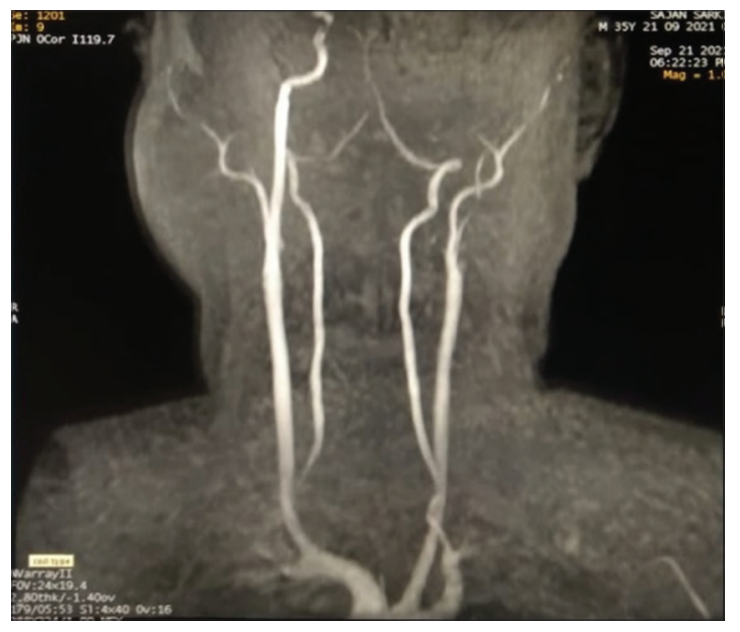

Figure 3: MR Angiography of the neck showing a very thin Left ICA not visible beyond the petrous bone in its intracranial course
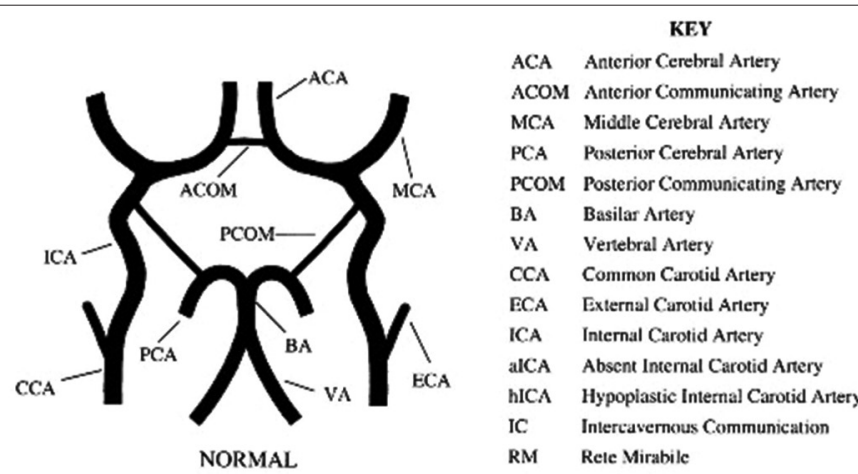

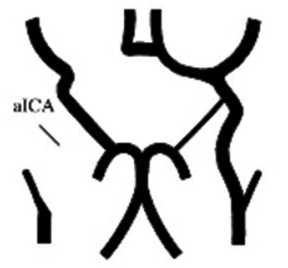

Type A

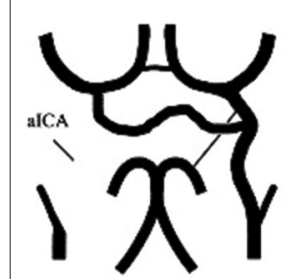

Type D

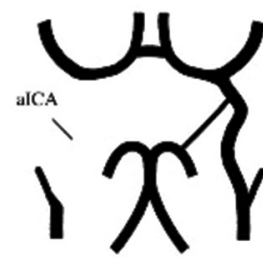

Type B

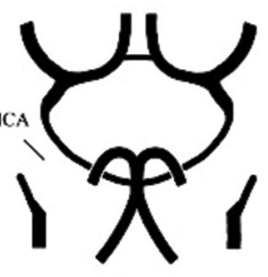

Type C
Figure 4: Absence of the ICA: pathways of collateral blood flow. AfterLie [11] and Quint et al. [15] 
childhood indicating that collaterals develop which are generally sufficient to maintain cerebral perfusion. Many of these cases go undiagnosed and uneventful throughout life. Some present with features of cerebrovascular insufficiency. There is an increased risk of patients having transient ischemic attacks as seen in this case [12]. Furthermore, these patients have a high incidence of a circle of Willis aneurysms [13].

Patients may present with recurrent headaches, blurring vision, loss of hearing, hemiparesis, quadriparesis, or cranial nerve palsy. Patients may also present with subarachnoid hemorrhage as a complication of an associated aneurysm rupture. Hence, early diagnosis is of paramount importance. And in already diagnosed cases, patients should be monitored for existing aneurysms and the development of new ones [14].

Non-visualization of the carotid canal on a CT scan should be regarded as highly suspicious for a congenital ICA abnormality and should prompt an extensive search for associated intracranial vascular malformations [15]. Our patient was discharged with the advice of regular follow-up with MRI and MR angiography at repeated intervals. CT angiography gives better anatomical delineation of the cerebral vessels and is cheaper as compared to MRI but there is a risk of hazard associated with radiation and contrast administration. MR Angiography is costly but has no associated radiation or contrast hazard. Another cheaper alternative is the carotid doppler study which is cheaper and faster and can raise suspicion of altered vascular anatomy. Sonographic features include non-visualization of ICA, high resistance waveform in ipsilateral CCA with externalization, high-velocity low resistance flow in the contralateral ICA as it has to compensate for the absent ICA on the opposite side.

\section{CONCLUSION}

Congenital absence of ICA is a rare congenital anomaly. Some cases are asymptomatic and some present with symptoms of cerebrovascular events. Early diagnosis and periodic screening are necessary as these patients are at increased risk of cerebrovascular events, development, and ruptures of aneurysms. Screening may be done with MR angiography or $\mathrm{CT}$ angiography. In young adults who present with recurrent stroke-like symptoms, it is better to investigate the patient with carotid doppler at least once. Normal arterial anatomy of neck vessels on doppler will rule out this anomaly with sufficient confidence and help in narrowing down an alternate diagnosis.

\section{REFERENCES}

1. Given CA, Huang-Hellinger F, Baker MD, Chepuri NB, Morris PP. Congenital absence of the internal carotid artery: Case reports and review of the collateral circulation. AJNR Am J Neuroradiol 2001;22:1953-9.

2. Afifi AK, Godersky JC, Menezes A, Smoker WR, Bell WE, Jacoby CG. Cerebral hemiatrophy, hypoplasia of internal carotid artery, and intracranial aneurysm. A rare association occurring in an infant. Arch Neurol 1987;44:232-5.

3. Yilmaz C, Utebay B, Kalaycioglu S, Onat G, Solak A. Non-visualization of the internal carotid artery with a normal ipsilateral common carotid artery Doppler waveform: A finding suggesting congenital absence of the ICA on colour Doppler ultrasound. Br J Radiol 2006;79:945.

4. Orakdögen M, Berkman Z, Ersahin M, Biber N, Somay H. Agenesis of the left internal carotid artery associated with anterior communicating artery aneurysm: Case report. Turk Neurosurg 2007;17:273-6.

5. Verbiest $\mathrm{H}$. Radiological findings in a case with absence of the left internal carotid artery and compression of several cranial nerve roots in the posterior fossa by the basilar artery. Med Contemp 1954;72:601-9.

6. Erdogan M, Senadim S, Yasinoglu KN, Selcuk HH, Atakli HD. Internal carotid artery agenesis with an intercavernous anastomosis: A rare case. J Stroke Cerebrovasc Dis 2017;26:2442-5.

7. Kishore PR, Kaufman AB, Melichar FA. Intrasellar carotid anastomosis simulating pituitary microadenoma. Radiology 1979;132:381-3.

8. Given CA, Huang-Hellinger F, Baker MD. Congenital absence of the internal carotid artery: Case reports and review of the collateral circulation. AJNR Am J Neuroradiol 2001;22:1953-9.

9. Lee JH, Oh CW, Lee $\mathrm{SH}$, Han DH. Aplasia of the internal carotid artery. Acta Neurochir (Wien) 2003;145:117-25; discussion 125.

10. Florio F, Balzano S, Nardella M, Strizzi V, Cammisa M, Bozzini V, et al. Congenital absence of the internal carotid artery. Cardiovasc Intervent Radiol 1999;22:74-8.

11. Lie TA. Congenital Anomalies of the Carotid Arteries. Amsterdam: Excerpta Medica; 1968. p. 35-51.

12. Babichev KN, Savello AV, Svistov DV, Kandyba DV, Barashkov EM. Segmental agenesis of the cervical internal carotid artery with collateral blood supply from the ascending pharyngeal artery and intercavernous anastomosis: A clinical case and literature review. Zh Vopr Neirokhir Im N N Burdenko 2018;82:81-7.

13. Park YW, Yoo J, Kim DJ. Double inter-internal carotid artery communication through intercavernous anastomosis and posterior communicating artery associated with multiple intracranial artery segmental agenesis/aplasia. Surg Radiol Anat 2018;40:227-31.

14. Oz II, Serifoglu I, Yazgan O, Erdem Z. Congenital absence of internal carotid artery with intercavernous anastomosis: Case report and systematic review of the literature. Interv Neuroradiol 2016;22:473-80.

15. Quint DJ, Boulos RS, Spera TD. Congenital absence of the cervical and petrous internal carotid artery with intercavernous anastomosis. AJNR Am J Neuroradiol 1989;10:435-9.

Funding: None; Conflicts of Interest: None Stated.

How to cite this article: Das U, Sahajada S, Ramudar S, Narayan P. Unilateral absence of internal carotid artery: A rare case report. Indian J Case Reports. 2021;7(12):532-534. 